\title{
ОБЗОР СУБТРАКТИВНОГО И АДДИТИВНОГО ПРОИЗВОДСТВА СЪЕМНЫХ ПРОТЕЗОВ ДЛЯ БЕЗЗУБЫХ ЧЕЛЮСТЕЙ
}

\section{OVERVIEW OF SUBTRACT AND ADDITIVE REMOVABLE PROSTHESIS FOR PLAINED JAWS}

A. Ertesyan

M. Sadykov

A. Nesterov

Summary. Complete dentures are technologically simple to manufacture, but they require a large number of clinical and technological steps, which can lead to an increased risk of errors. With the development of digital technologies, subtractive and additive methods, the workflow has been significantly reduced, and the accuracy of prosthetic devices has increased significantly. These technologies use industrially produced materials with physical, chemical and mechanical properties superior to conventional materials. The main motives for adopting or rejecting a new technology are the relative advantages they offer over classical methods, and these can be represented by time savings, financial benefits, and clinical benefits. The present study aims to analyze the advantages and disadvantages of digitally fabricated full dentures.

Keywords: complete removable plate prosthesis, CAD / CAM, 3D printing, additive technologies, subtractive technologies, STL.

\author{
Эртесян Альберт Робертович \\ К.м.н., ассистент, ФГБОУ ВО «Самарский \\ государственный медицинский университет» \\ Минздрава России, Самара \\ albertertesyan@gmail.com \\ Садыков Мукатдес Ибрагимович \\ Д.м.н., профессор, ФГБОУ ВО «Самарский \\ государственный медицинский университет» \\ Минздрава России, Самара \\ Нестеров Александр Михайлович \\ Д.м.н., профессор, ФГБОУ ВО «Самарский \\ государственный медицинский университет» \\ Минздрава России, Самара
}

Аннотация. Полные протезы технологически несложно изготовить, но они требуют большого количества клинических и технологических этапов, что может привести к повышенному риску ошибок. С развитием цифровых технологий, субтрактивных и аддитивных методов рабочий поток значительно сократился, а точность протезных устройств значительно повысилась. Вэтих технологиях используются материалы промышленного производства, с физическими, химическими и механическими свойствами, превосходящими обычные материалы. Основными мотивами для принятия или отказа от новой технологии являются относительные преимущества, которые они предлагают по сравнению с классическими методами, и они могут быть представлены экономией времени, финансовыми преимуществами и клиническими преимуществами. Настоящее исследование направлено на анализ преимуществ и недостатков полных протезов, изготовленных цифровыми методами.

Ключевые слова: полный съемный пластиночный протез, CAD/CAM, 3D печать, аддитивные технологии, субтрактивные технологии, STL.

эстетический вид, хорошая теплопроводность, низкая проницаемость для жидкостей полости рта, стабильность цвета, низкое водопоглощение, низкая растворимость, точное воспроизведение деталей поверхности, малый вес и невысокая стоимость $[1,2,3]$.

Но эти материалы также имеют ряд недостатков, таких как: плохие механические свойства, высокий коэффициент теплового расширения, низкий модуль упругости, повышенный риск разрушения, раздражение слизистой оболочки, вызванное высвобождением метилметакрилата или бактериальной колонизацией из-за их пористости. [4]. Пористость протеза может потенциально привести к увеличению накопления биопленки 
в полости рта и увеличению количества микроорганизмов, вызывающих протезный стоматит. Для устранения этих недостатков и улучшения свойств акриловых пластмасс были проведены многочисленные исследования. Эти исследования были направлены на разработку альтернативных материалов, на изменение и оптимизацию структуры полимеров или на увеличение механической прочности метилполиметакрилата [5].

Важной проблемой, с которой столкнулись стоматологи-ортопеды, это раздражение слизистой оболочки, вызванное микробной адгезией к внутренней поверхности протеза. Эпидемиологические исследования показывают, что примерно 70\% пациентов с полными съемными протезами страдают протезным стоматитом. Адгезия Candida albicans и образование биопленки считаются важными предпосылками протезного стоматита. [7,8,9,10]. Другая проблема, связанная с протезным стоматитом, заключается в том, что некоторым пожилым пациентам трудно содержать протез в чистоте из-за их пониженной двигательной активности, потери памяти и когнитивных нарушений [11]. Классическое лечение протезных стоматитов основано на местных или системных противогрибковых препаратах [12], но эта инфекция часто носит стойкий характер, поскольку в биопленках Candida albicans имеется резистентность к противогрибковым препаратам [13]. Профилактика протезного стоматита по-прежнему представляет собой проблему для стоматологии, и необходимы дополнительные исследования, чтобы найти оптимальный метод профилактики. чтобы обеспечить антибактериальные свойства, в последние годы все больше внимания уделяется включению AgNps (наночастицы серебра) в акриловые смолы. Включение AgNPs направлено на предотвращение или, по крайней мере, уменьшение микробной колонизации на стоматологических материалах, улучшение параметров здоровья полости рта и улучшение качества жизни $[14,15]$.

Изготовить полные съемные пластиночные протезы технологически несложно, но они требуют большого количества клинических и технологических этапов, поэтому существует повышенный риск ошибок. С развитием цифровых технологий, субтрактивных и более поздних аддитивных методов рабочий процесс был значительно сокращен, а точность ортопедических конструкций значительно возросла. В этих технологиях используются материалы промышленного производства, с физическими, химическими и механическими свойствами, превосходящими обычные материалы. Основными мотивами для принятия или отказа от новой технологии являются относительные преимущества, которые они предлагают по сравнению с классическим методом, которые могут быть представлены экономией времени, финансовыми преимуществами и клиническими преимуществами [8].

\section{Цель исслеАования}

Анализ преимуществ и недостатков полных съемных пластиночных протезов, изготовленных цифровыми методами.

\section{Материалы \\ исслеАования}

Компьютерное проектирование / компьютерное производство (субтрактивные технологии). Компьютерное проектирование / компьютерное производство (CAD/CAM) становится все более популярным в стоматологии, особенно при изготовлении несъемных протезов. Технологии CAD/CAM для изготовления полных съемных пластиночных протезов стали более известными и коммерчески доступными, а методы и материалы становятся все более эффективными, что позволяет получать полные съемные протезы в соответствии с самыми высокими требованиями. Эти процедуры предлагают значительные преимущества стоматологу-ортопеду, зубному технику, а также пациентам. Технология CAD/ САМ включает три важных этапа: сбор данных с помощью внутриротовых сканеров или сканирование гипсовой модели, создание виртуальных конструкций для будущих протезов и компьютеризированная реализация полного съемного пластиночного протеза, используя самые современные материалы.

Пластмассы для изготовления полных съемных пластиночных протезов, используемые в компьютеризированных технологиях, производятся промышленным способом, обладают высокой устойчивостью к ударам и деформациям, устойчивостью к побледнению, стабильностью цвета и стабильностью размеров. Форполимеризованная акриловая смола производится под высоким давлением, при нагревании и полимеризационной усадке не происходит, уменьшается пористость и снижается прилипание Candida albicans к основе протеза. Отсутствие полимеризационной усадки, связанной с фрезерованными зубными протезами, приводит к высокоточной точности полного съемного протеза и улучшенной ретенции.

Кроме того, в основе CAD/CAM-протеза, изготовленного из дисков из полиметилметакрилата, полимеризованной при высокой температуре и давлении, снижен риск образования остаточного мономера. Остаточный мономер обуславливает токсичность, низкие механические свойства акриловых смол и низкое водопоглощение. Кроме того, метилметакрилат связан с реакциями иммунной гиперчувствительности в деснах и слизистой оболочке, а также с системными реакциями из-за небольшого размера молекул, которые могут диффундировать по всему телу. 
Преимущество использования форполимеризованных смол заключается в более высокой степени превращения мономера, что приводит к образованию более длинных полимерных цепей, полимеризационная усадка уже реализована, можно ожидать повышения точности съемного протеза.

Цифровыми методами можно изготовить не только базис полного съемного протеза, но и искусственные зубы, при этом можно получить искусственные дуги индивидуальной морфологии, с высокой прочностью и эстетикой.

У технологий CAD/CAM также есть ограничения и недостатки: межчелюстное соотношение, поддержка губ и положение режущего края верхней челюсти затруднены, оптимальная оценка вертикального размера, установление окклюзионной плоскости нижней челюсти затруднены, возможность для участия пациента во время процедуры минимально, текущие затраты на материалы и лабораторию по-прежнему дороже по сравнению с изготовлением традиционными методами.

Технология 3D печати (аддитивные технологии). Технологии 3D-печати представляют собой еще одну возможность создания полных съемных пластиночных протезов компьютеризированными методами. Технологии аддитивного производства - это, по сути, метод получения устройств со сложной пространственной геометрией с помощью аддитивных процессов. Аддитивное производство быстро набирает обороты почти во всех областях стоматологии, и оно отличается от формирующего и субтрактивного производства, в процессе аддитивного производства устройство печатается путем добавления материала слой за слоем. По сравнению с субтрактивной технологией CAD/CAM для разработки съемных протезов, основанной на фрезеровании с компьютерным управлением, 3D-печать предлагает преимущество неограниченной гибкости дизайна, поскольку разработка протезного устройства осуществляется в несколько простых шагов.

Основными этапами конструирования полных съемных пластиночных протезов являются: наложение слоев фотополимерной смолы в горизонтальном направлении и их последовательная полимеризация в вертикальном направлении; удаление конструкций, необходимых для поддержки устройства при реализации (стержни также предотвращают деформацию перед полной полимеризацией); удаление остатков неполимеризованного материала.

Клинико-технологический процесс изготовления полного протеза включает несколько этапов: сканиро- вание, проектирование, вывод файла в формате STL, печать и постобработка, сборка, окончательное постотверждение и отделка.

Сначала получают цифровой оттиск с беззубой челюсти пациента или гипсовой модели. Наилучший доступный метод создания цифрового файла для пациентов с полной адентией - сканирование полностью сочлененной залитой модели и восковой оправы с помощью настольного лабораторного сканера.

После вывода файла STL следует этап печати и постобработки. После экспорта файлов STL для дизайна съемного протеза его можно импортировать в программу, которая содержит файлы для печати, и можно выбрать материал для печати зубного протеза. Зубы или базис съемного протеза.

После того, как фотополимерная смола помещена в резервуар, можно начинать печать. 3D-печать заключается во введении платформы для выполнения предлагаемых съемных протезов в ванну с фотополимерной смолой, на которую нанесен равномерный слой смолы микрометрического размера в соответствии с программой CAD3D design. После того, как этот первый слой материала полимеризован, процедура продолжается путем последовательного послойного осаждения и полимеризации жидкой смолы до тех пор, пока не будет получена окончательная форма полного съемного протеза. Ортопедическая конструкция, напечатанная на 3D-принтере, соединена с производственной платформой некоторыми опорными элементами из того же типа смолы. Далее следует этап постобработки, который включает промывку изопропиловым спиртом и удаление несущих конструкций.

На следующем этапе изготовления полных съемных протезов, искусственные зубы устанавливают и приклеивают к базису. На этом этапе протез готов к окончательному отверждению при температуре $80{ }^{\circ} \mathrm{C}$ в течение 30 минут. После завершения постотверждения следует заключительный этап, он также выполняется, как и для традиционного полного съемного пластиночного протеза, путем полировки на малых оборотах тряпичным кругом на шлифовальном станке с пемзой.

3D-печать имеет ряд преимуществ по сравнению с традиционной технологией: высокая точность, достигаемая благодаря аддитивной технологии, которая по сравнению с субтрактивными методами позволяет превосходно воспроизводить детали; повышение производительности труда, возможность одновременно выполнять несколько работ, снижение расхода стоматологических материалов и рабочего времени. 
К недостаткам можно отнести высокую стоимость программ цифровой обработки и самих принтеров, более ограниченную доступность материалов для этой технологии [23].

\section{ВывО $\triangle \mathrm{b}$}

Цифровые технологии улучшили качество полных съемных пластиночных протезов в стоматологии и нашли способ стандартизировать производственный процесс. Программные решения CAD/CAM предназначены для создания, обработки, анализа и управления трех- мерными данными для применения в сложных производственных процессах.

Цифровой процесс протезирования представляет собой возможность цифрового проектирования и производства полных съемных пластиночных протезов. Качество и долговечность сравнимы с традиционными протезами, а часто даже превосходят их, потому что эти технологии позволяют использовать современные материалы с оптимизированными механическими и биологическими характеристиками.

\section{ЛИТЕРАТУРА}

1. Lee HH, Lee CJ, Asaoka K. Correlation in the mechanical properties of acrylic denture base resins. Dent Mater J., 31(1), 157-164, 2012

2. Tandon R, Gupta S, Agarwal SK. Denture base materials: From past to future. Indian Journal of Dental Sciences. 2(2), 33-39, 2010

3. Mohamed H, 0 Assery AS., Mansour K, Braka E, Vellappally A. S., Anil SA. Comparative Study of the Mechanical Properties of the Light-cure and Conventional DentureBase Resins. OHDM. 13 (2), 311-315, 2014

4. Ali IL, Yunus N, Ibrahim M. Hardness, flexural strength, and flexural modulus comparisons of three differently cured denture base systems. J Prosthodont. 17, 545549,2008

5. Chand P, Patel CB, Singh BP, Singh RD, Singh K. Mechanical properties of denture base resins: an evaluation. Indian J Dent Res. 22(1), 180-185, 2011

6. Эртесян А.Р., Садыков М. И., Нестеров А. М. Обзор технологий 3D — печати в стоматологии / А. Р. Эртесян, М. И. Садыков, А. М. Нестеров // Медико-фармацевтический журнал «ПУЛЬС».— 2020 — Том. 22.— № 10.— С. 15-18. http://dx.doi.org/10.26787/nydha-2686-6838-2019-22-10

7. Эртесян А.Р., Садыков М. И., Нестеров А. М. Обзор биосовместимых фотополимерных смол для съемного протезирования // Современная наука: актуальные проблемы теории и практики: Серия «Естественные и Технические науки».— 2020.— № 11.— C. 205-208. D0I 10.37882/2223-2966.2020.11.3

8. Эртесян А.Р., Садыков М. И., Нестеров А. М., А. Р. Сараев Сравнительная оценка экономического обоснования и эффективности изготовления полных съемных пластиночных протезов, полученных с помощью традиционных и 3D технологий // Современная наука: актуальные проблемы теории и практики: Серия «Естественные и Технические науки».— 2020.— № 11.— C. 209-213. D0I 10.37882/2223-2966.2020.11.37

9. Kang SH, Lee HJ, Hong SH, Kim KH, Kwon TY. Influence of surface characteristics on the adhesion of Candida albicans to various denture lining materials. Acta Odontologica Scandinavica. 71(1), 241-248, 2013

10. Sobolewska E, Fraczak B, Czarnomysy-Furowicz D, Ey-Chmielewska H, Karakulska J. Bacteria adhesion to the surface of various prosthetics materials. AnnAcad Med Stetin. 53(2), 68-71, 2007

11. Kassaee M.Z., Akhavan A., Sheikh N., Sodagar A. Antibacterial effects of a new dental acrylic resin containing AgNps. Journal of Applied Polymer Science. 2008;110(3):1699-1703.

12. Rowan R., McCann M., Kavanagh K. Analysis of the response of Candida albicans cells to Silver(I) Medical Mycology. 2010;48(3):498-505 13. Kong H., Jang J. Antibacterial properties of novel polymethylmethacrylate nanofiber containing AgNps. Langmuir. 2008;24(5):2051-2056.

13. Diaconu-Popa D, Viţalariu A, Tatarciuc M, Munteanu F. Effect of silver nanoparticles incorporation in dental resins on stress Distribution-Finite Element Analysis. Rev. chim.(Bucharest). 67(8), 1571-1574 2016

14. Ertesyan A.R., Sadykov M. I., Nesterov A. M. 3D Technologies In Dentistry// Proceedings of the XIII-XIV International Multidisciplinary Conference «Recent Scientific Investigation». Primedia E-launch LLC. Shawnee, USA. 2020. https://www.internauka.org/conf/usa\#articles (дата обращения: 07.11.2020)

15. Sodagar A., Kassaee M.Z., Akhavan A., Javadi N., Arab S, Kharazifard M. J. Effect of silver nano particles on flexural strength of acrylic resins. Journal of Prosthodontic Research 56(2), 120-124, 2012

(с) Эртесян Альберт Робертович ( albertertesyan@gmail.com ),

Садыков Мукатдес Ибрагимович, Нестеров Александр Михайлович.

Журнал «Современная наука: актуальные проблемы теории и практики» 